\title{
The value of advocacy: putting ethics into practice ${ }^{\dagger}$
}

\author{
Philip F. Thomas and Patrick Bracken
}

The days when patients gratefully tugged their forelocks and deferred to the doctor's superior knowledge and social status have gone. Since the middle of this century, consumerism has dominated all aspects of our society, health care included, changing people's expectations of their relationships with health care professionals, especially doctors. These changes are reflected in a spate of government papers, such as The Patient's Charter' (Department of Health, 1991), 'Priorities and Planning Guidance for the NHS' (NHS Executive, 1995) and 'Local Voices: the Views of People in Purchasing for Health' (NHS Management Executive, 1992). The problem, as Williams \& Grant (1998) point out, is that these documents generally pay little attention to how those who use the National Health Service (NHS) see their needs. Indeed, recent tragic events in Bristol might lead us to conclude that in reality nothing has changed, with doctors working secretively and putting their professional interests before those of their patients. The use and misuse of medical power, whether in paediatric cardiology or psychiatry, requires a very clear response. Here, we shall argue that advocacy has a key role to play in mediating the dangers of unchecked medical paternalism in psychiatry. Indeed, as the government is about to announce the outcome of its review of mental health services, with the introduction of assertive outreach teams and compulsory treatment in the community, the ethical checks and balances introduced by advocacy have never been more important.

\section{What is advocacj?}

Before defining advocacy, it is important to be clear about what advocacy is not. Because advocates often come into conflict with professionals, psychiatrists mistakenly dismiss advocacy as 'anti-psychiatry'. As Peter Campbell points out. psychiatrists and other professionals use this epithet whenever their professional judgement is challenged. According to Campbell

'See invited commentary p. 330, this issue.
(1996), advocacy has played a central role in the history of the user/survivor movement in the UK. Although the movement originally had affinities with, and was inspired by, the work of Laing. Szasz and Cooper, the present-day user movement's relationship to 'anti-psychiatry' is more spiritual than practical.

The UK Advocacy Network (UKAN) is a federation of independent patients' councils, advocacy projects and user forums for mental health service users and has produced (UKAN \& the NHS Executive, 1997) one of the clearest descriptions of advocacy. Advocates are trained to assist people with mental health problems in making their own informed choices, and to help protect their rights and interests. Advocacy can occur individually or by helping groups of service users to influence the planning and delivery of mental health services. The UKAN identifies five types of advocacy, but those that have the greatest impact on psychiatry are peer advocacy and self-advocacy. There is a lengthy tradition of peer advocacy in the UK. This involves support from advocates who have experienced mental health problems themselves, and is usually provided by an independent advocacy service either in the community or in mental health units. Self-advocacy, which is usually the ultmate objective of peer advocacy, occurs when people are able to speak out for themselves.

\section{Advocacy, autonomy and paternalism}

There is a strong case to be made in support of advocacy if we examine doctor-patient relationships from an ethical perspective. Consider this extract from the UKAN document:

The presence of peer advocates within services and the community gives powerful messages, both to the people who call on them and the people from services who encounter them in the course of their work. of the cultural shift in attitude and ethos required. when doing things with people instead of to them and for them."

(UKAN \& the NHS Executive, 1997; emphasis added)

Doing things to or for people lies at the heart of medical paternalism, and this takes us to three 
relevant aspects of doctor-patient relationships; autonomy, paternalism and beneficence.

Gillon (1986) describes autonomy (or self-rule) as the capacity to think, decide and act independently, without constraint. It is an important concept in Western philosophy and can be traced back through Kant to Aristotle, both of whom considered it to be a feature of rational beings. There are three types of autonomy: autonomy of thought involves our freedom to make decisions for ourselves, as well as having beliefs and making moral judgement; autonomy of will is our freedom to decide to do things on the basis of our thought and it is this that is most likely to be affected by illness; and autonomy of action is our freedom to act on the basis of our decision to act. It is also important to distinguish between autonomy and the principle of respect for autonomy, or the moral requirement that we respect other people's autonomy.

Paternalism applies when a doctor acts in what he or she considers to be the patient's best interest, whether or not the patient happens to agree. In some situations it is obvious that such action must be taken, for example in life or death situations. Paternalism is as old as medicine itself, and is seen in the Hippocratic Oath:

"I will follow that system or regimen which, according to my ability and judgement. I consider for the benefit of my patients."

Paternalism is acceptable in so far as it is genuinely concerned with the patient's 'benefit', and this leads to the principle of beneficence: the idea that we should do good for others.

Both society and the medical profession assume that doctors have a responsibility to do good for the benefit of the sick, but although most people would agree that we have a duty not to do each other harm, it does not follow that we have a duty to do good. Paternalism acting under the guise of beneficence is fraught with difficulties, and can lead to the assumption that patients are incapable of making decisions about their treatment and that they should not be involved in such decisions. This is particularly likely to occur when the patient has a condition such as mental illness, which is believed to impair judgement. The problem here is that medical paternalism assumes that the only bases on which treatment decisions should be made are medical ones. This view disregards the importance of personal lay-beliefs about the nature and meaning of illness and personal preferences about treatment. For example, the adverse effects of one treatment may have devastating implications for one patient's life, whereas another patient may find the same adverse effects acceptable. It is presumptuous for a doctor to believe that he or she knows what is best for a particular patient.

\section{Ethical dilemmas and conflicts}

In psychiatry there are many situations in which paternalism, beneficence and autonomy come into conflict, and it is in these conflicts that we can see the real value of advocacy. Perhaps the most common situation concerns the implications that having a label of mental illness has for autonomy. We have already seen that autonomy and rationality are closely linked. It is often assumed that in irrational states, such as psychosis, there are constraints on a person's ability to act autonomously. This view may be used as justification by a psychiatrist to disregard the patient's treatment preferences. But situations in which a person is irrational in all aspects of thought, will and action are rare, and there may well be very good reasons for a patient preferring not to follow a course of action suggested by a psychiatrist, such as previous experiences of side-effects of a particular treatment. Advocacy has an important role to play in the process of negotiation around treatment. There will inevitably be situations where agreement between the two sides - patient and psychiatrist - will be impossible to achieve, and it is in these situations that the psychiatrist will feel most threatened by the advocate's support for the patient's position. A patient steadfastly refusing a course of treatment, supported by an advocate, against the will of the clinical staff is one of the most difficult ethical dilemmas to resolve.

One way around some of these problems is through crisis cards and advanced directives. This is a form of self-advocacy in which a person who may occasionally have problems with autonomy through mental illness provides instructions, when well, about the type of help he or she wants to receive when unwell. The crisis card is the simplest form of self-advocacy and carries details of who to contact in an emergency. Advanced directives contain more detailed instructions about the help and support that an individual prefers, including where help should be provided and the type of medication to be given or not to be given. At the moment, the legal status of advanced directives has yet to be established, but it has the potential to play an important part in ensuring that a person's wishes are fulfilled if that person's autonomy is temporarily restricted.

Another dilemma can arise through the principle of respect for autonomy. The idea that we have a moral requirement to respect other people's autonomy can lead to some very difficult situations. For example, if a patient is detained 
in hospital because he or she believes that a neighbour is poisoning him or her, and they have threatened to kill the neighbour, we remove his or her civil liberties and constrain their autonomy. This action is justifiable because if the patient's autonomy was allowed to continue unchecked, the neighbour's autonomy would be jeopardised, breaching the principle of respect for autonomy. Under such circumstances, advocacy is valuable because it can balance the need for compulsory detention and treatment against the person's right to be heard.

\section{The profession and advocacy}

It is inevitable that, in representing the patient's interests, advocates will come into conflict with psychiatrists. But if advocacy is to be successful in its difficult task of balancing the professional's view with the patient's interests, it is important that psychiatry moves away from a negative 'anti-psychiatry' view of advocacy to a more constructive engagement. There is very little in the psychiatric literature on advocacy, apart from a report for the College's Public Policy Committee (Royal College of Psychiatrists, 1989). Recently, the College has established a working party, through the Patients' and Carers' Liaison Group, with representation from UKAN and MENCAP. The draft report, which is described as a policy document with recommendations for good practice, reviews the different types of advocacy and spells out their benefits. It also outlines the ethical code for advocates and describes their training. It is difficult to find fault with the report, but the main problem concerns Its reception by, and status within, the College. The best way for psychiatrists to understand the purpose of advocacy is for them to be exposed to it during their training. At present there appears to be no mechanism to enable this to take place. College requirements for training make no reference to the value or importance of advocacy. This could be rectified by including a section on advocacy in the recently introduced log-book system for trainees. The paid participation of service users in locally organised training schemes for psychiatrists should be a mandatory requirement for the approval of such schemes by the College.

The report on advocacy also raises the wider issue of the relationship between the College and the user movement. The recent history of this relationship is not a comfortable one, but the need to improve the situation is now greater than ever. The establishment of the Patients' and Carers' Liaison Group was a step in the right direction, but the time is now right for the College to review the structure and function of this body. It should be expanded to include a wider range of voices, in response to the growth of advocacy and the diverse groups who represent the concerns of different users. There must be mechanisms to ensure that such a body has greater influence on College policy, especially in the areas of training and education. Advocacy at the individual level must be complemented by advocacy at the institutional level. As long as trainee psychiatrists have no exposure to advocacy and advocates in their training. they will remain in ignorance of the importance of advocacy and will continue in the mistaken belief that a challenge from an advocate is a personal attack motivated by 'anti-psychiatry'.

\section{References}

CAMPBEL. P. (1996) The history of the user movement in the United Kingdom. In Mental Health Matters: a Reader (eds T. Heller et al). pp. 218-225. London: Macmillan.

DEPARTMENT OF HEALTH (1991) The Patient's Charter. London: HMSO.

Gillon, R. (1986) Philosophical Medical Ethics. Chichester: Wiley.

NHS Executive (1995) Priorities and Planning Guidance for the NHS: 1996/97. Leeds: NHSE.

NHS Management Executive (1992) Local Voices: the Views of People in Purchasing for Health. Leeds: NHSME.

Royal College OF PSYChIATRSTS (1989) Patient advocacy Report for Public Policy Committee. Psychiatric Bulletin. 13, 715-716.

UKAN AND THE NHS EXECUTTVE (1997) Advocacy - a Code of Practice. Leeds: United Kingdom Advocacy Network \& Mental Health Task Force User Group.

WiLLAAMS, B. \& GRANT, G. (1998) Defining 'people centredness': making the implicit explicit. Health and Social Care in the Community. 6. 84-94.

*Philip F. Thomas and Patrick Bracken, Senior Research Fellows and Consultant Psychiatrists, Department of Social \& Economic Studies, University of Bradford, Richmond Bullding, Richmond Street, Bradford BD7 6DP, UK

\section{*Correspondence}

